\title{
Conceptual view of Cyberloafing and Non-Work Domain
}

\author{
Patrick Chin-Hooi Soh ${ }^{1,}$, Klan-Yeik Koay ${ }^{2}$, and Kok-Wai Chew ${ }^{3}$ \\ ${ }^{1,2,3}$ Multimedia University, Cyberjaya 63100, Malaysia
}

\begin{abstract}
In an attempt to understand the reasons for employees' personal Internet use at work, known as cyberloafing, this paper attempts a new perspective to look at the phenomenon. As the barrier between the previously separate work and home domains reduces, employees are increasingly integrating their working and private world. This phenomenon has resulted in employees using their personal time for work-related tasks through technology in the privacy of their homes and private domain. Conversely, employees could be carrying out non-work related Internet use during office hours. This paper aims to explore the possibility of non-work domain as a factor for employees to cyberloaf. This paper proposed a conceptual model based on border theory and theory of interpersonal behaviour. The resultant augmented theory offers a richer explanation of how non-work domain affects employees' decision making process on cyberloafing.
\end{abstract}

\section{Introduction}

In a book named Work/Life Collision written by [1], the author describes about the collision between work and life with its subsequent impact to the society, families, and individuals in Australia. It was observed that there are drastic changes in household patterns with rising number of singlehood, single-parents households and dual-income earners households, more participation of women in labor force seeking for jobs and wealth, a redistribution of working hours and a greater emphasis on work-life-balance. These phenomena are even more conspicuous in today's world as compared to 12 years ago, when the book was written. Combined with the rapid advancement of technology that allows communications without geographical constrains, this has greatly minimized the barrier between the traditional boundary of work and family domains. These trends have driven employees to integrate their work and family domains. For example, employees in United States work at home twice a week [2]. Apart from that, utilizing the technology to perform work-related tasks such as checking office email, receiving instant messages from customers or colleagues and bringing office work home to do after official working hours has been a common practice. In today's global economy, it is prevalent for companies having businesses around the world. This leads to the need of employees of multinationals

* Corresponding author: chsoh@mmu.edu.my 
meeting their counterparts who stay across continents with different time zones via teleconference late at nights or even in the early mornings for meetings.

To compensate the sacrifices of personal time for work-related purposes, employees may feel less guilty in and reciprocate by engaging non-work-related online activities during working hours for personal errands or stress relief. However, most of the organizations abhor employees from cyberloafing due to its negative ramifications such as clogging up networks bandwidth, degrading system performance [3], putting organizations at risk for legal liabilities (e.g., employees download illegal music or watch offensive videos) [4-7], and reducing job productivity. Surveys found that sixty one percent of American employees engage in non-work related activities during working hours and fiftysix percent of their time online, in fact, doing non-work related activities $[8,9]$. About $20 \%$ to $30 \%$ of companies have terminated employees for cyberloafing activities like accessing pornographic sites, online gambling, and online shopping [10]. Given that there is no comprehensive framework that includes the potential impact of non-work domain in explaining employees' cyberloafing behaviour in the current literature, this conceptual paper seeks to:

1) Extends the theory of interpersonal behaviour by explaining the role of private demands and importance of non-work domain in affecting employees' cyberloafing behaviour

The resultant augmented theory provides a richer explanation of cyberloafing intention and behavior.

\section{Theoretical background}

This section explains Clark's work/family theory [11] and Triandis's theory of Interpersonal behavior [12]. Subsequently, we propose 6 propositions based on both theories in order to have a better understanding on how non-work domain affecting employees' decision making process on cyberloafing.

Border theory argues that people proactively try to attain work life balance and reduce role conflicts by constantly crossing the borders between work and non-work in order to satisfy both needs [11]. Changes in household patterns with rising number of dual-income and single-parent households have caused people holding multiple roles and responsibilities both at home and at work. As a result, in an attempt to manage the unique needs of each domain, people often crossing the border of work and family through communications and other actions. Following the logic and reasoning behind the border theory posits, this suggests that private demands can be a source of motivation for employees to use the Internet for non-work-related online activities. Private demands refer to family/social demands outside of the work domain. Employees may hold different roles such as being the breadwinner for the family or a part-time English teacher of tuition centre with various obligations and responsibilities in the society. Hence, employees with more private demands are more likely to fulfill those needs through using the Internet at work. For example, employees might use their Internet to buy movie tickets, pay home bill or arrange transportation to pick up their children from school due to working overtime. This is a concern in today's modern society where both parents are earning to support the family. As such, communication and coordination between family members are frequently done through during office hours.

A theory developed by Triandis to explain various types of human behavior named theory of interpersonal behavior (TIB) has been applied in the context of cyberloafing and proven to have a strong exploratory power on cyberloafing in previous empirical studies $[12,13,14]$. The theory postulates that a person's intention to act a certain behavior is best 
predicted by his or her perceived consequences, affect and social factors. On the other hand, the set of precursors that determine an individual's actual behavior are habit, intentions, and facilitating conditions.

Perceived consequences in this paper refers to "the degree to which cyberloafing behavior is valued positively or negatively by the individual; it is an assessment of the total set of outcomes that result from using the Internet for non-work related reasons during office hours" [14]. TIB posits that any behavior will generate a form of positive or negative outcomes which are evaluated subjectively by the individual based on the perceived degree of benefits and penalty. Affect refers to feelings of like and dislike felt by an individual when performing cyberloafing behavior [12]. The emotion linked to cyberloafing vary from exciting, happy, disgusting, dull or hatred, depending on how the individual perceive of cyberloafing [14]. When cyberloafing is seen as an enjoyable activity by employees, it is more likely they will form the intention to employ the Internet connection for cyberloafing. In this paper, social factors refer to the degree to which the perceived social pressure from important referent groups on the use Internet for non-work-related purposes in the workplace [12]. For example, referent groups include the employee's family, friends, coworker, supervisor, IT department and top management. The influence of each social group on employees' cyberloafing very much relies on the perceived importance of the particular group by employees. When cyberloafing is perceived to be an acceptable behavior by others such as colleagues, top management or friends, the individual will be more likely to form intention to cyberloafing. Conversely, when people perceive their social networks disapprove of cyberloafing activities, the intention to cyberloaf will not be formed.

Facilitating conditions refer to factors within the individual's environment which are perceived to facilitate or impede the performance of certain behavior. Facilitating conditions can be classified into two dimensions [14]. First dimension refers to situational factor consisting of external conditions and access to the resources. Second dimension refers to internal factor referring to a person's self-efficacy to use the Internet to cyberloaf. For example, organizations that implement tight Internet monitoring system and follow strictly to the Internet usage policy, these impediments will reduce the likelihood of employees from cyberloafing [16]. In the same vein, employees who have the intention to cyberloaf without the access to the Internet access may not translate into actual behavior. Furthermore, the capability to use the Internet for personal reasons is crucial as ones must at least know how to technically utilize the technology given.

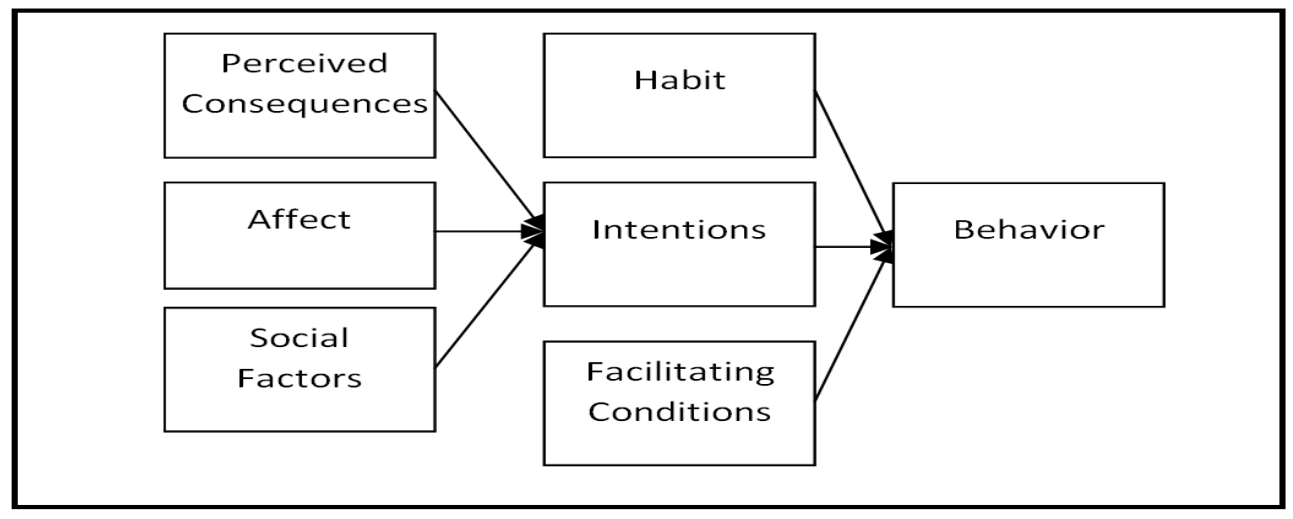

Fig 1. Theory of Interpersonal Behavior

Although theories and previous studies have provided indications on the possible impact of non-work domain in affecting employees' cyberloafing behavior, surprisingly the extant theories of cyberloafing in current literature have not explicitly considered them, including 
TIB. To date, there is only a single study by [17] reporting that private demands have a positive relationship with cyberloafing. However, the underlying mechanism that private demands drives cyberloafing remains unknown for researchers. In this paper, we propose 6 prepositions to extend the existing theory of Interpersonal behavior, so that future researchers can take into consideration of the impact of non-work domain on employees' decision making process on cyberloafing.

P1: Private demands have a positive relationship with Perceived Consequences for Cyberloafing.

When employees utilize their private time (usually occurs at home) for work-related reasons, they are likely to feel justified to use their office hours to use the Internet for nonwork related reasons. For example, an employee who spend hours at nights in the home doing work-related research would probably have little qualms to use part of his working hours in the office for online entertainment, relaxation or to maintain friendship through social networking sites. Another example is that an employee should have paid his monthly installment for his loan via online payment after working hours at night. However, due to he is so busy to finish his works until late night, he has forgotten to pay his bill. As a result, the needs to pay the bill may convert to (higher positive) perceived consequences for cyberloafing during work hours in view of the penalties of charges for late payments.

P2: Private Demands has a positive relationship with Affect for Cyberloafing.

To the extent that cyberloafing can be used to resolve private demands, employees will want to seek satisfaction in their work/life balance. For example, employees may seek to communicate with their loved ones on what time he/she is returning home for dinner, or perhaps after an argument with their spouse or turn to online gaming for escape from marital stress.

\section{P3: Private Demands have a positive relationship with Social Factors for Cyberloafing.}

In this current technological age, family, friends and social contacts regularly communicate with each other real-time and online through instant messaging, Facebook, Twitter etcetera. It follow then that people will perceive their friends and colleagues to be less disapproving (and might even be expecting) the use of the Internet for personal matters during working hours.

P4: Importance of non-work domain moderates the relationship between Private demands and perceived consequences for cyberloafing

P5: Importance of non-work domain moderates the relationship between Private demands and perceived consequences for cyberloafing

P6: Importance of non-work domain moderates the relationship between Private demands and perceived consequences for cyberloafing

Home/family, friends, community are the constituents of an individual's non-work domain. The priority people place on their work, home, or leisure is not the same and largely depends on cultural context and a person's life stage [18]. Work-oriented people may be dedicated to his or her job and thus the likelihood of them cyberloafing due to the influence of non-work domain will be lower as compared to nonwork-oriented people. For work-oriented people, cyberloafing may not be perceived as providing significant positive consequences such as maintaining relationship with family or friends or saving time for personal commitments, and generating positive affect such as happiness, loving or caring. Furthermore, young people who are at the beginning of their career might want to put more emphasis on their work rather than home or leisure. Consistent with this reasoning, the 
impact of private demands on perceived consequences, affect and social factors for cyberloafing is very much determined by the weights given to non-work domain by the employees.

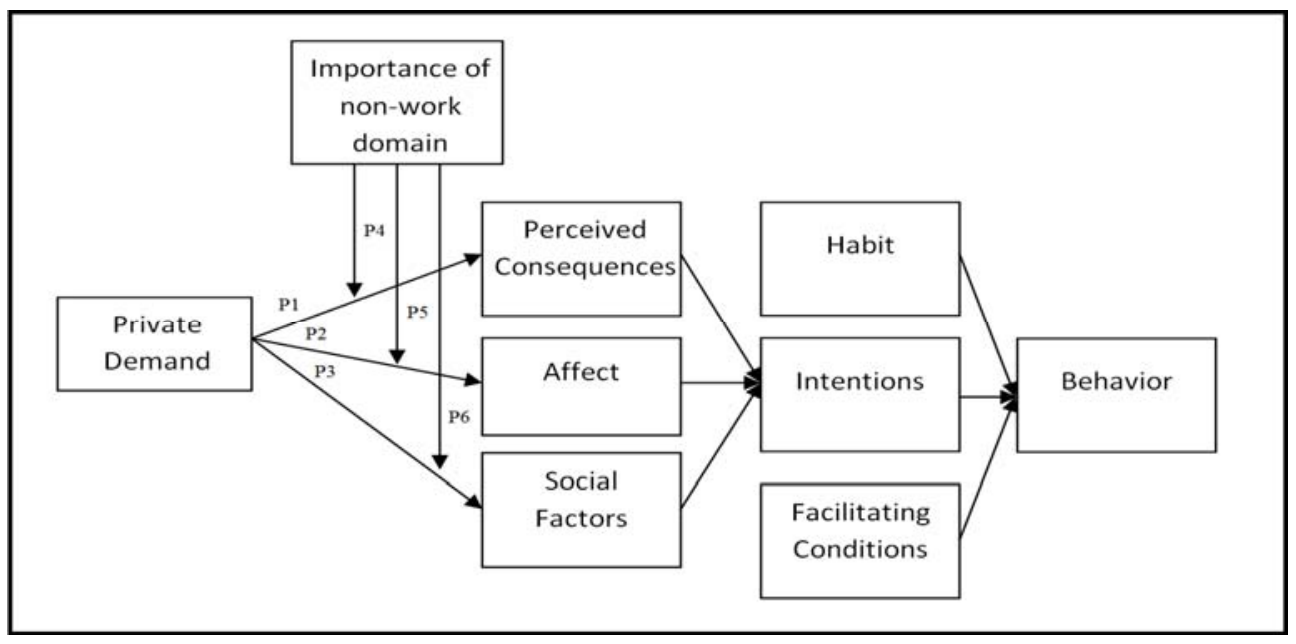

Fig. 2. Augmented Theory of Interpersonal Behavior

\section{Conclusion}

This conceptual paper attempts to explain the role of private demand and the moderating role of the importance of non-work domain on cyberloafing behavior through an extension of the theory of interpersonal behavior (TIB). As the boundary between work and private lives is becoming more intertwined, people need to balance their work and private domains. One chief means of balancing work and private domain is cyberloafing during office hours.

Future studies should empirically test the proposed conceptual framework to find out whether employees' non-work domain plays a substantial role in affecting cyberloafing behaviour.

\section{References}

1. B. Pocock, B. The Work/life Collision: What Work is Doing to Australians and what to Do about it: The Federation Press (2003)

2. Gallup News Service. Gallup Polll Social Series: Work and Education. In J. Jones \& L. Saad (Eds.): Gallup News Service. (2005)

3. J. C. Sipior, B. T. Ward, A Strategic Response to the Broad Spectrum of Internet Abuse. Inform Syst Magage, 19, 71-79 (2002)

4. A. E. Lichtash, Inappropriate use of e-mail and the Internet in the workplace: The arbitration picture. Dispute Resolot J, 59, 26-36 (2004)

5. J. E. Mills, B. Hu, S. Beldona, J. Clay, Cyberslacking! A liability Issue for Wired Workplaces. Cornell Hotel RestauR Adm, 42, 34-47 (2001)

6. R. R. Panko, H. G. Beh, Monitoring for pornography and sexual harassment. Commun ACM, 45, 84-87 (2002)

7. L. R. Scheuermann, H. P. Langford, H. P, Perceptions of Internet abuse, liability, and fair use. Percepl and Motor Skill, 85, 847-850 (1997)

8. I. Websense, Web@Work Employee Computing Trends Survey (2006) 
9. MySammy, Cyberloafing Infographic: Personal Internet Use at Work Infographic. (2013)

10. C .J. Case, K. S. Young, Employee Internet Management: Current Business Practices and Outcomes. CyberPsychology \& Behaviour, 5, 355-361 (2002)

11. S. C. Clark, Work/family border theory: A new theory of work/family balance. Hum Relat, 53, 747-770 (2000)

12. H. C. Triandis, Values, Attitudes, and Interpersonal Behaviour.In H. Howe \& M. Page (Eds.), Nebraska Symposium on Motivation, 1979, 195-295. Lincoln, NE: University of Nebraska Press (1980)

13. G. D. Moody, M. Siponen, Using the Theory of Interpersonal Behaviour to Explain Non-Work-Related Personal Use of the Internet at Work. Inform Manage, 50, 322-335 (2013)

14. L. G. Pee, I. Woon, A. Kankaanhalli, A, Explaining non-work related computing in the workplace: A comparison of alternative models. Inform Manage, 45, 123-130 (2008)

15. T. K. Betts, A. J. Setterstrom, J. M. Pearson, S. Totty, Explaining Cyberloafing through a Theoretical Integration of Theory of Interpersonal Behaviour and Theory of Organizational Justice. J Organ End User Comput, 26, 23-42 (2014)

16. J. C. Ugrin, M. J. Pearson, The Effects of Sanctions and Stigmas on Cyberloafing. Hum Behav, 29, 812-820 (2013)

17. C. J. König, M. E. Caner de la Guardia, Exploring the Positive Side of Personal Internet Use at Work: Does It Help in Managing the Border between Work and Nonwork? Computer Human Behavior, 30, 355-360 (2014)

18. E. R. Eddy, C. P. D'Abate, P. W. Thurston Jr, Explaining engagement in personal activities on company time. PERS REV, 39, 639 - 654 (2010) 